\title{
O cotidiano de trabalhadores domiciliares da indústria calçadista: percepções e vivências sobre trabalho e tempo livre
}

\section{The routine of footwear industry home workers: perceptions and experience about work and free time}

\author{
Suzi Mara Freitas* \\ Discente de Psicologia do Centro Universitário de Franca - Uni-FACEF, Franca, SP, \\ Brasil
}

\section{Daniela de Figueiredo Ribeiro**}

Docente do Departamento de Psicologia do Centro Universitário de Franca - UniFACEF, Franca, SP, Brasil

\section{Antônio dos Santos Andrade***}

Docente do Departamento de Psicologia e Educação da Faculdade de Filosofia Ciências e Letras de Ribeirão Preto da Universidade de São Paulo-FFCLRP/USP, Ribeirão Preto, SP, Brasil

\begin{abstract}
RESUMO
O presente artigo é um estudo que visa compreender como o trabalho e o tempo livre são percebidos e vividos por atores sociais que partilham de uma realidade onde o ambiente de trabalho se funde ao meio doméstico. A coleta de dados foi realizada em duas etapas: a primeira, chamada fase exploratória, caracterizou-se pela execução de observações participantes em dez residências nas quais os trabalhadores exerciam suas atividades e, na segunda fase, chamada focalizada, foram efetuadas entrevistas individuais e semiestruturadas com cinco trabalhadores, em suas residências-oficinas. Os dados obtidos foram analisados por meio da abordagem hermenêuticadialética, permitindo verificar que os participantes se definem pela capacidade em criar momentos de flexibilidade durante o trabalho, o que resulta em um ambiente mais descontraído que o da fábrica. Entretanto, ao se colocarem como seus próprios patrões, observa-se um desgaste de suas capacidades físicas e emocionais, com decorrente dificuldade em utilizar o tempo livre.
\end{abstract}

Palavras-chave: Trabalho, Tempo livre, Trabalhadores da indústria calçadista.

\section{ABSTRACT}

The present paper is a study which seeks to understand how work and free time are experienced by social actors that share a reality where work and domestic environment are mixed. The data collection was carried out in two stages: the exploratory phase in which ten residences were observed, where 
workers developed their activities; and the focalized phase, in which five workers were interviewed at their home-work places. The obtained data were analyzed through hermeneutic dialetic analysis. It allowed verifying that the participants are defined by the capacity in creating moments of flexibility during work time, which results in a more casual atmosphere than the one of factories. However, as they are their own bosses, it leads to physical and emotional wear and tear and difficulties in managing free time.

Keywords: Work, Free time, Footwear industry workers.

\section{I ntrodução}

Waichman (1997) caracteriza o tempo livre a partir de duas concepções: a primeira, em oposição ao trabalho; a segunda, com ênfase na liberdade, embora sem exatidão sobre o sentido ou significado desse conceito. Posteriormente, o autor define o tempo livre como um período no qual o homem age por sua própria necessidade, sendo que as condições para a realização de cada atividade podem ser colocadas ou impostas, dependendo do condicionamento que surge em razão de obrigações exteriores à conduta.

Portuguez e Rabelo (2001) definem também o tempo livre como um período de não trabalho, podendo este ser preenchido por outras atividades, tais como o lazer. Esse aspecto é compreendido como uma das tantas dimensões que formam o tempo livre, segundo os autores.

Codina (2002, apud SARRIERA; PARADISO; MOUSQUER; MARQUES; HERMEL; COELHO, 2007), Cunha (1987, apud SARRIERA; PARADISO; MOUSQUER; MARQUES; HERMEL; COELHO, 2007), Zamora, Toledo, Santi, Martinez (1995, apud SARRIERA; PARADISO; MOUSQUER; MARQUES; HERMEL; COELHO, 2007) afirmam que o tempo livre pode ser um espaço onde o indivíduo dá vazão às suas expectativas, podendo, assim, escolher as atividades que deseja realizar. O modo como o indivíduo desfruta o tempo livre está ligado às conjunturas social, cultural, econômica, ideológica e física, nas quais está inserido, incluindo variáveis psicológicas individuais.

Do mesmo modo Sarriera, Paradiso, Mousquer, Marques, Hermel, Coelho (2007) definem o tempo livre a partir de questões individuais, considerando também o meio em que o indivíduo está inserido. Tais autores, ao realizarem uma pesquisa acerca do significado do tempo livre para adolescentes de classe popular, verificaram que “(...) mesmo diante de carências financeiras e investimento social, os adolescentes sabem organizar seu tempo livre destacando, sobretudo, a interação social" (SARRIERA; PARADISO; MOUSQUER; MARQUES; HERMEL; COELHO, 2007, p.728).

Para cada um de nós, tempo livre significa viagem, cultura, erotismo, estética, repouso, esporte, ginástica, meditação e 
reflexão. Significa, antes de tudo, nos exercitarmos em descobrir quantas coisas podemos fazer, desde hoje, no nosso tempo disponível, sem gastar um tostão: passear sozinhos ou com amigos, ir à paria, fazer amor com a pessoa amada, adivinhar os pensamentos, os problemas $e$ as paixões que estão por trás dos rostos dos transeuntes, admirar os quadros expostos em cada igreja, assistir a um festival na televisão, ler um livro, provocar uma discussão com um motorista de táxi, jogar conversa fora com os mendigos, admirar a sábia beleza de uma garrafa ou de um ovo (...) (DE MASI, 2000, p.321).

O autor citado acima, em sua obra O Ócio Criativo, afirma que uma parte do tempo livre deve ser dedicada ao cuidado com o corpo e com a mente, outra parte deve ser dedicada à família e aos amigos e uma terceira parte deve ser dedicada à coletividade, incluindo a organização civil e política. Ele descreve ainda a dificuldade de se viver o tempo livre e a atual dependência psicológica do trabalho, ou seja, o overtime, que em inglês significa "além do tempo". Neste contexto, o indivíduo se habitua de tal forma ao trabalho que quando está fora dele se sente perdido, desorientado e inútil.

Em síntese, observa-se que o tempo livre é visto e definido por todos autores até aqui citados como o inverso do tempo de trabalho, uma vez que ele abre espaço para vivências pessoais e autorrealizadoras. Entretanto, na medida em que o indivíduo se torna psicologicamente dependente do trabalho, como pontua De Masi (2000), o tempo livre pode vir a ser um evento que também produz tensão e sofrimento.

Tal aspecto pode estar relacionado à segunda afirmativa de Waichman (1997), que considera as atividades realizadas durante o tempo livre conectadas às exigências externas, bem como às idéias de Sarriera; Paradiso; Mousquer; Marques; Hermel; Coelho (2007), os quais afirmam que tais atividades estão relacionadas a questões individuais e ao ambiente social partilhado.

Em uma sociedade capitalista, onde o trabalho é supervalorizado, a vivência do tempo livre torna-se um desafio não apenas no aspecto concreto e temporal, como também na possibilidade de se ter experiências autorrealizadoras que não estejam ligadas ao ideário cultural mais amplo. De forma mais ou menos sutil, esse ideário acaba por ditar a maneira como os indivíduos devem vivenciar seu tempo livre.

Oliveira (2004) afirma que o trabalho é produto do homem e, ao mesmo tempo, produtor da cultura e civilização humana. Trabalhar tem o significado de garantir as condições para o desenvolvimento da existência do homem, o que só poderia trazer satisfação e prazer.

No entanto, o trabalho vem causando tensão e sofrimento devido ao sistema produtivo capitalista, o qual se baseia na exploração do tempo de trabalho e não permite a criatividade e o usufruto de seus 
resultados. O momento de labor acaba sendo sinônimo de tempo das necessidades, e as horas livres e de lazer são deslocadas para o mesmo fim. Neste mesmo sentido, Chenavier (1998) afirma que a necessidade é essencial à atividade, para que a mesma não se torne vazia e sem sentido. Entretanto, a necessidade não pode ser o centro da atividade, pois isso pode levar à servilização dessa mesma atividade. Aquino e Martins (2007, p. 481) acrescentam que:

(...) no caos entre necessidades econômicas e existenciais, o homem contemporâneo se vê dividido entre as obrigações impostas por suas atividades laborais e o desejo de libertarse dessas tarefas e, assim, poder usufruir um tempo para si. (AQUINO; MARTINS, 2007, p. 481).

Marcellino (2004) observa ainda um paradoxo: para usufruir o lazer e o tempo livre é preciso reduzir a jornada de trabalho, mas se a mesma for reduzida, não haverá renda suficiente para cobrir as despesas exigidas por esses momentos. Por conseguinte, 0 trabalhador se vê obrigado a trocar esse tempo para responder às exigências do mercado.

Segundo Portuguez (2001), o modelo pós-moderno de vida urbana causou nas classes menos favorecidas uma preocupação em buscar, durante as horas livres, uma complementação de renda por meios informais, enquanto as classes mais privilegiadas desfrutam do tempo de não trabalho. Em razão disso, muitas vezes a residência acaba deixando de ser o cenário ideal para o refúgio seguro ou para a convivência familiar e assume funções distintas, como ser o local adequado para a execução dos negócios.

O aumento do setor informal de prestação de serviços tem influenciado não somente a produção industrial, como também a maneira de viver das pessoas que presenciam essa realidade. Como afirmam Barbosa e Mendes (2003), no caso dos trabalhadores domiciliares da indústria calçadista que realizam um trabalho terceirizado em bancas de pesponto, não é possível distinguir onde começa a oficina ou termina a casa, já que essas bancas são instaladas em ambientes improvisados ou adaptados, na própria moradia do trabalhador.

De acordo com Navarro (2003), as pequenas bancas de pesponto contam com a ajuda de uma ou mais pessoas da família para a execução do trabalho. As de porte médio empregam de 15 a 20 trabalhadores e as grandes dispõem de instalações onde trabalham centenas de funcionários subcontratados. A maior parte das pequenas bancas funciona de maneira informal, onde muitos de seus trabalhadores não possuem carteira assinada e, portanto, não usufruem dos mesmos direitos que aqueles considerados formais, tais 
como férias, décimo terceiro, seguro desemprego, salário mensal estável e carga horária fixa de trabalho.

$\mathrm{Na}$ cidade em que foi realizada a pesquisa, a maioria dos trabalhadores vive nesta situação de trabalho domiciliar e informalidade, uma vez que a economia local gira em torno da indústria calçadista. A partir da década de 90 , esse setor vem passando por um processo de reestruturação produtiva, com importante aumento na terceirização de serviços.

Diante de tal realidade e das mudanças decorrentes do modo de produção e estilo de vida dos trabalhadores, a atual pesquisa teve como objetivos:

1) investigar como os trabalhadores utilizam as possibilidades que estão ao seu alcance para desfrutar e vivenciar o tempo livre; 2) identificar o modo como eles percebem seu trabalho; 3) investigar as possibilidades de descanso físico e ou psicológico dos trabalhadores, bem como as oportunidades de dedicação a si mesmos.

\section{Método}

Para a realização do presente estudo foi utilizada a proposta qualitativa que, de acordo com Minayo (1996), baseia-se na investigação de diferentes significados de experiências vividas, proporcionando uma fiel compreensão do indivíduo em seu contexto. Em conjunto com ela, foi utilizada a abordagem etnográfica que, para André (2004), busca desvendar os significados expressos pela linguagem, ações e eventos que os sujeitos ou grupos pesquisados usam para organizar seus comportamentos.

\subsection{Participantes}

$\mathrm{Na}$ primeira etapa da pesquisa, caracterizada por observações participantes em dez residências de trabalhadores, fizeram parte ao todo cinqüenta e quatro pessoas, sendo vinte e sete do sexo feminino e vinte e sete do sexo masculino. Em três residências, os moradores se caracterizavam por trabalhar em bancas de pesponto e, nas outras sete residências, os moradores trabalhavam manualmente com a costura do sapato.

Os critérios de inclusão dos participantes foram: 1) morar no bairro estudado (tipicamente operário); 2) possuir banca de pesponto ou trabalhar com a costura manual na própria residência. Foram excluídos os participantes que, naquele momento, realizavam um trabalho temporário com o calçado.

\subsection{Operacionalização}

A coleta de dados aconteceu em duas fases, descritas a seguir. 


\section{I - Fase exploratória}

Foram realizadas observações participantes em três residências onde funcionavam, concomitantemente, bancas de pesponto. Também, em sete residências onde era realizada a costura manual do calçado, sendo este serviço terceirizado pelas bancas de pesponto.

O primeiro contato com os participantes da pesquisa aconteceu pela mediação de uma assistente social responsável pelo trabalho técnico e social do Bairro Jardim Andorinha ${ }^{1}$. Inicialmente, foram contatados os líderes comunitários, os quais apresentaram as integrantes do grupo de pesquisa ${ }^{2}$ aos moradores que trabalhavam em suas residências, prestando serviços à indústria calçadista local.

A pesquisadora foi apresentada em particular para o morador da residência na qual ficaria responsável pela coleta de dados. Ficou esclarecido, dessa forma, que o propósito da observação participante se resumia em compreender o contexto em que eles, os participantes da pesquisa, inseriam-se, além de ter sido explicitado o sigilo em não expor nomes e resultados que pudessem fazer com que outras pessoas os identificassem ${ }^{3}$. Os dados obtidos durante o trabalho de observação foram registrados em diário de campo e avaliados por meio de uma análise de conteúdo tradicional, como propõe Bardin (1977) e Minayo (1996).

\section{I - Fase focalizada}

Foram realizadas entrevistas individuais, semiestruturadas, com cinco dos trabalhadores identificados na etapa anterior da pesquisa. As entrevistas foram gravadas e transcritas na íntegra para posterior análise. O roteiro de entrevista consistiu na investigação sobre as concepções e vivências relativas ao trabalho e tempo livre.

\subsection{Análise de dados}

Foi utilizado o método hermenêutico-dialético de análise. Tal abordagem complementa os estudos etnográficos, uma vez que promove um olhar voltado para as entrelinhas do contexto vivenciado pelos sujeitos.

$\mathrm{Na}$ abordagem hermenêutica-dialética, a interpretação compreende dois níveis:

1) nível das determinações fundamentais: trata-se do contexto sócio-histórico do grupo social estudado, ou seja, a participação dessa população enquanto atores sociais que partilham da conjuntura sócio-político-econômica atual, a história do grupo social e sua inserção na produção capitalista - o sistema de trabalho, de moradia e de organização social;

2) nível do encontro com os fatos empíricos: análise das entrevistas e diários de campo, proporcionando a identificação das categorias de análise. 
As categorias analíticas foram construídas a partir da literatura específica sobre a área, enquanto as categorias empíricas, a partir da prática em campo. Operacionalmente, os dados foram ordenados para a construção de um mapa horizontal das descobertas: transcrição de fitas, releitura do material, organização do relatório e dos dados de observação. A classificação dos dados foi feita a partir da leitura exaustiva e repetida dos textos, permitindo apreender as idéias centrais sobre o tema.

\section{Resultados e discussão}

Os resultados foram obtidos por meio das observações participantes realizadas na primeira fase da pesquisa, bem como a partir das entrevistas individuais semiestruturadas, executadas na segunda fase do presente estudo. Essas duas perspectivas permitiram a descrição de aspectos relacionados ao contexto de vida dos participantes e, ao mesmo tempo, suas percepções e vivências quanto ao tempo livre e ao trabalho.

\subsection{Resultados da fase exploratória}

O bairro Jardim Andorinha é caracterizado por ser um bairro novo, de casas populares, construídas sobre um terreno de planalto, por intermédio de um Programa de Habitação Popular.

Nele, não há creches, escolas, postos de saúde, farmácias, praças, clubes, centro comunitário ou casas lotéricas. Tampouco há igrejas, sendo os cultos e missas realizados nas residências dos moradores. Contudo, a Igreja Católica ganhou um terreno para sua construção e vem arrecadando fundos com a realização de quermesses. Em razão, ainda, da falta de uma biblioteca pública, um dos moradores disponibilizou sua casa para tal fim e, desde então, vem recebendo doações de livros.

Há ainda uma grande quantidade de terrenos baldios, um campo de terra, telefones públicos, uma mercearia e um supermercado. Recentemente, foram abertas uma papelaria, uma padaria, uma lan house e uma sorveteria, sendo todos esses pontos de comércio localizados na avenida central.

O transporte público passa pelo bairro de 20 em 20 minutos, durante a semana, e de 30 em 30 minutos, aos finais de semana. Dispõe-se também de um ônibus escolar oferecido pela prefeitura. Quanto à segurança, alguns moradores consideram o bairro Jardim Andorinha seguro, outros não. A ronda policial é solicitada pelos moradores para que passe várias vezes durante a noite pelas ruas.

Foi observado que as casas, quando entregues aos moradores, caracterizavam-se por sua padronização, ou seja, seguiam o mesmo tamanho e número de cômodos. Em geral, as residências possuíam dois quartos, um banheiro, uma cozinha e um quintal. As reformas feitas na parte interna ou externa das casas, tais como calçada, 
pintura, garagem, muros, portões, entre outros, foram acontecendo aos poucos, de acordo com as possibilidades dos residentes.

Com relação à movimentação do bairro, na sua maioria são moradores do local que transitam pelas ruas, sendo geralmente ciclistas, grupos de adolescentes e crianças. No período noturno, há maior movimentação do que durante o dia. As opções de atividades de lazer no bairro são jogos de futebol masculino aos finais de semana, festas em datas comemorativas e quermesse uma vez por ano. As crianças costumam soltar pipas nas ruas e em terrenos baldios.

A partir das observações participantes realizadas nas residências, pôde-se observar que, no caso das pessoas que trabalham manualmente com a fabricação do calçado, tal atividade geralmente é desenvolvida na sala ou na varanda da residência, em contato direto com o ambiente familiar. Já nas residências que possuem bancas de pesponto, o trabalho é realizado em um cômodo separado, mas que ainda favorece um contato diário entre os membros da família.

\subsection{Resultados da fase focalizada}

A partir dos dados obtidos nas entrevistas individuais foram construídos dois focos temáticos: Tempo Livre e Trabalho, onde serão expostos os conteúdos das falas dos entrevistados ${ }^{4}$. Concomitante a isso, será realizada a discussão dos resultados.

\section{Foco temático I - Tempo livre}

Apenas um entrevistado revelou sua percepção sobre o tempo livre, já que os outros trouxeram somente conteúdos vivenciais. Tal entrevistado colocou que as pessoas são as responsáveis pela distribuição de seu tempo e, por isso, podem desfrutar dos benefícios do tempo livre. Não são todos, porém, que conseguem isso, como pode ser observado em seu relato:

"A gente que faz o tempo, né? Por que tempo tem bastante, mas a gente que não, que não faz esse tempo pra podê curtir" (Pereira).

Assim, o único participante que fala de tempo livre dá uma conotação individual para tal conceito, enfatizando a questão de que está nas mãos de cada pessoa conseguir esse momento.

A tese levantada por esse participante faz sentido, uma vez que ele está inserido em uma realidade onde é seu próprio patrão e, portanto, pode controlar seu tempo. Por um lado, em uma situação onde as pessoas são seus próprios patrões, aparentemente está nas mãos delas o controle do tempo livre, pois elas estão imersas em um contexto em que sua liberdade é relativa. Por outro lado, nota-se no 
relato do trabalhador que ele não parece identificar claramente as variáveis macrossociais que determinam as possibilidades disponíveis, tanto nas formas de se executar o trabalho quanto nas de se vivenciar o tempo livre.

Três entrevistados afirmaram desfrutar do tempo livre. No entanto, cada um o utiliza de uma forma diferente: uma participante brinca com os filhos, outro participante descansa aos finais de semana e ajuda na igreja e um terceiro participante assiste à tevê no horário de almoço, como pode ser verificado nos relatos abaixo:

\footnotetext{
"A gente tira um tempo livre. Tira assim, brincando com as crianças né? Eu tenho que tirar um tempo pra eles. É, tira, às vezes sobra, né? (Neide).
}

“Ah, meu tempo livre, assim, eu utilizo ajudando na igreja no fim de semana, no sábado, né? E no domingo. Na parte da manhã a gente descansa um pouco, né?" (Renato).

“(...) na hora do almoço, assim, quando você tem aquele tempo livre, assim, pra almoçar sossegado, aí o que, que eu faço? Vô pra dentro almoçá e fico assistindo na televisão o desenho, curtindo um desenho, assim, né?" (Pereira).

Quando os participantes da pesquisa descrevem as atividades realizadas durante o tempo livre, tal como a realização de brincadeiras com os filhos e a prática de atividades religiosas, percebe-se uma relação desses aspectos com a definição apresentada por De Masi (2000), que caracteriza o tempo livre como um tempo para dedicação à família, amigos e à coletividade. De acordo com esse autor, os participantes vivenciam o tempo livre, ainda que tais vivências sejam reconhecidas somente nas minúcias do cotidiano.

Os baixos salários, o excesso de trabalho e a precária infraestrutura de serviços do bairro dificultam as vivências durante esse tempo, mas não as eliminam, já que atividades como jogos de futebol masculino aos finais de semana, festas comemorativas, quermesse anual e brincadeiras com pipas nas ruas e em terrenos baldios, são comuns no cotidiano dessas pessoas.

É notável ainda que em um ambiente onde se fundem atividades lúdicas e estratificadas, trabalho obrigatório e atividades domésticas, além da aparente liberdade em determinar o tempo para começar e parar o trabalho, o desejo de usufruir do tempo livre pode se apresentar, ao mesmo tempo, como um fator ansiogênico para essa população.

Como é ressaltado por um dos entrevistados, a definição de cada um desses momentos depende de suas próprias escolhas. À medida que ocasiões de descanso são priorizadas, emergem também a culpa e o medo gerados pela possibilidade de não cumprimento das responsabilidades assumidas, tão valorizadas em nossa sociedade. 


\section{Foco temático II - Trabalho}

Três entrevistados descreveram suas rotinas de trabalho. Um deles, alegando razões financeiras, relatou que, muitas vezes, durante a semana, precisa trabalhar após o expediente. Um segundo entrevistado afirmou trabalhar o dia inteiro, até a meia noite. O outro participante descreve que o trabalho obrigatório não deixa de fazer parte de sua rotina, até mesmo aos sábados, como é apontado em sua narração:

\footnotetext{
“(...) eu começo as sete, das sete as cinco da tarde, né? Mas, paro uma meia hora, vamos supor, tempo livre de uma hora, meia hora, né? É pouco, né? Tem dia que tem que trabalhá até mais tarde, nove, dez horas. Dia de sábado cê tem que trabalhá o dia inteiro, né? No domingo não procuro. No sábado, se eu tiver que trabalhá, tudo bem, mas no domingo, deixa quieto, né? (Pereira).
}

A realização das observações participantes foi fundamental para a compreensão do trabalho na vida dessas pessoas. Elas permitiram o contato direto com a realidade em questão, possibilitando verificar que as atividades têm como característica marcante o fato de serem precárias.

Além da baixa remuneração, com a presença de um intermediário, o qual detém parte do dinheiro que essas pessoas ganham, verificou-se uma explícita falta de vínculos com a fábrica. Quando há trabalho, os participantes são obrigados a aceitar as más condições, já que não existem garantias de que haverá serviço todos os dias. Ao longo do ano, foi possível notar que tais condições geram seu excesso em alguns períodos, pois essas pessoas são as responsáveis pela produtividade, a qual, por sua vez, determina a renda familiar no final do mês. Quando falta trabalho, mesmo que haja tempo livre, os entrevistados mostraram não o usufruir em razão das preocupações financeiras e instabilidade emocional, decorrentes desse contexto.

Oliveira (2004) e Camargo (1992) apontam o trabalho como causador de sofrimento devido ao sistema produtivo capitalista, baseado na exploração do tempo e do trabalho, não permitindo a criatividade e inibindo qualquer forma de diversão. Além disso, a precariedade do trabalho é perceptível. Ter seu próprio negócio é ainda mais cruel, já que é muito difícil lidar com a concorrência e a instabilidade que decorrem desta forma de produção. Ainda assim, esses trabalhadores acabam se iludindo, acreditando que estão realizando o trabalho da maneira deles e que é muito mais vantajoso serem seus próprios patrões.

Com relação aos significados atribuídos ao trabalho, nota-se que todos os entrevistados o veem como um meio de suprir as 
necessidades financeiras, que muitas vezes aparecem vinculadas a sonhos de adquirir bens materiais.

Dois entrevistados falaram do trabalho como forma de prover tais necessidades relacionadas à sobrevivência. Uma entrevistada salientou que através do cumprimento desta tarefa é possível ajudar seu marido nas despesas domésticas. Outro enfatizou a necessidade de se ter uma atividade, bem como a importância em sentir prazer com ela.

Dois participantes apontaram que quanto mais trabalham, mais gastam. Desse modo, acabam tendo de produzir ainda mais para recuperar o "prejuízo", obrigando-os a deixar as atividades de lazer de lado, como pode ser exemplificado nos relatos abaixo:

\footnotetext{
“Mas no caso também, no dia que você trabalha em casa, você fazendo um pouco mais, talvez cê ganhe um pouquinho mais, mais aí cê gasta um pouquinho mais, aí você fala, vixi, hoje vou ter que trabalhá um pouco mais pra podê, né? e a gente acaba trabalhando mais do que o normal, né? Mais horas. Então tem muito isso também (...)"

“(...) cê tem essa jogada de fazê também, né? trabalho hoje, amanhã eu descanso, né? Tem hora que você não consegue disfazê do serviço durante o dia, então cê tem que trabalhá um poquim a mais, né?" (Pereira).
}

Diante dos dados apresentados, verifica-se que a amostra estudada está de acordo com as afirmações de Marcellino (2004). O autor pontua que para usufruir o tempo livre é preciso reduzir a jornada de trabalho, mas se a mesma for reduzida, não haverá renda para o lazer. Como resultado dessa lógica, o trabalhador nega seu tempo de descanso para responder às exigências do mercado, repetindo, assim, o ciclo vicioso relatado.

Observa-se ainda que, uma vez que o trabalho se torna presente no espaço familiar dessa população, forma-se um ambiente propício de empreendimento. O agenciamento coletivo, próprio do capitalismo, acaba sendo adotado e a rede de controle e servilização se converte em invisível, já que o suprir as necessidades básicas de sobrevivência passa a depender do monitoramento próprio.

Quanto aos aspectos positivos do trabalho domiciliar com o calçado, dois participantes enfatizaram a possibilidade de passarem mais tempo com os filhos. Um participante relatou que, trabalhando em casa, pode usar a roupa que se sente à vontade para a realização das atividades. Dois participantes valorizaram a flexibilidade de horário para a execução do trabalho remunerado, como é ilustrado pela fala de Neuza:

"Acho que favorece, igual, eu tô em casa, o dia que eu não posso pegar serviço, eu aviso. Pra mim não tem problema, né? Eu posso parar aqui na hora que eu quiser, quando eu 
tenho alguma coisa pra fazer, aí eu pego menos serviço, né?" (Neuza).

No que se refere aos aspectos negativos, uma participante fez menção ao trabalho excessivo, às dificuldades em montar os diferentes modelos de sapato e aos gastos extras no orçamento da família, pois a banca de pesponto fica instalada no quintal de sua casa. Isso pode ser exemplificado pelo seguinte discurso de Benedita:

“O lado negativo aí é você trabalhá dentro de casa, você trabalha muito, sabe? Come, trabalha, cê tem que entregar uma produção, aí cê tem que trabalhá mais, porque conforme o serviço você trabalha mais, cê corre, corre contra o relógio, o relógio é meu maior inimigo aqui dentro. Por que varia os modelo (de sapato), tem modelo que é uma benção, tem modelo que dá um trabalho, tem modelo que, sabe? E tem outra coisa também, a gente gasta mais, a gente gasta no dia-a-dia, no orçamento, se a gente sai de manhã pra trabalhá, e só volta de tarde, cê gasta menos, cê não tá gastando água, não tá gastando energia, telefone, nada" (Benedita).

Outra participante citou como aspecto negativo as constantes pressões que sofre por ser a responsável pela entrega do serviço na banca. Também, três participantes reclamaram da flexibilidade de horários, pois muitas vezes precisam ficar além do período estipulado para finalizar o trabalho, como pode ser observado no relato abaixo:

\begin{abstract}
“Então, assim, em determinadas situações, acaba prejudicando, por que às vezes as pessoas vem, chama a gente pra fazê alguma coisa, e cê não pode por causa do serviço. Que nem, estragô uma máquina, aconteceu alguma coisa e cê tem que recuperar na parte da noite, né? Já, se fosse na fábrica, deu o horário, daquela hora que você saiu, cê tá livre, né? Então ocê teria um tempo mais disponível, né?" (Renato).
\end{abstract}

Ao analisar os discursos apresentados pelos trabalhadores, observase a existência de dualidades, que são ressaltadas quando os participantes da pesquisa mencionam tanto os aspectos positivos como os negativos do trabalho domiciliar. Pode-se concluir que trabalhar em casa é, realmente, uma linha flexível, e neste ambiente existe mais maleabilidade do que na fábrica.

Desse modo, é possível considerar que esse tipo de trabalho acaba adquirindo duplo sentido. Se algumas vezes ele favorece momentos de maior flexibilidade, em outras ocasiões, o ser patrão de si mesmo exige algo além da capacidade física e emocional dessas pessoas. Inclui-se como consequência dessa forma laboral a já mencionada dificuldade do uso do tempo livre, como foi descrito por um 
entrevistado que relata que, durante seu período de folga, fica no ambiente da banca de pesponto procurando trabalho extra.

É interessante notar ainda que, em nenhum momento, os participantes da pesquisa mencionaram férias. Isso nos leva a inferir que nessa camada popular há poucas oportunidades para o uso do tempo livre, o que poderia ser uma das causas da execução do trabalho durante os horários em que, teoricamente, seriam destinados à prática de atividades lúdicas.

\section{Conclusão}

A partir da pesquisa realizada, pode-se concluir que a camada popular estudada se insere em um contexto onde as pessoas são constantemente atravessadas por momentos rígidos, que os levam ao cumprimento de um trabalho obrigatório, precário e mal remunerado. Ademais, cada trabalhador é levado a acreditar na aparente liberdade para determinar o seu próprio tempo de atividade, quando, na realidade, permanecem escravizados.

Por outro lado, estão presentes também no cotidiano desses trabalhadores momentos flexíveis que possibilitam a vivência de produção desejante. Como consequência, o ambiente de trabalho na residência se torna mais leve e descontraído, se comparado a uma fábrica.

O tempo livre, nesse contexto onde se fundem não somente 0 trabalho obrigatório e o trabalho doméstico como também atividades lúdicas e estratificadas, é reconhecido por meio das minúcias produzidas no dia-a-dia. Elas caracterizam uma nova forma para se vivenciar esse tempo, ainda que os baixos salários, o excesso de trabalho e a precária infraestrutura de serviços do bairro dificultem tais vivências.

Ressalta-se que este é um estudo preliminar, o qual proporcionou um contato inicial com uma limitada amostra de trabalhadores da camada popular brasileira. Isso implica na necessidade de realização de novos estudos que visem ampliar ou até mesmo aprofundar os resultados obtidos.

Como desdobramento da pesquisa, salienta-se que tem sido mantido o contato com a população do bairro, mediante um trabalho de psicologia comunitária. Em breve, deverão ser realizados grupos de encontros com os participantes da pesquisa e com outros moradores que vivenciam situações semelhantes.

Nesses encontros, serão explicitados os resultados obtidos no atual estudo, com o objetivo de levantar discussões que tenham como pauta a divisão do tempo de trabalho e tempo livre. Junto a esse aspecto, a contradição entre serem donos do tempo, mas não poderem usufruí-lo, em razão da carga horária de trabalho excessiva e a luta pela sobrevivência. 
Essa discussão terá como objetivo levar os trabalhadores a estabelecerem limites mais claros entre o máximo da carga horária de trabalho e o mínimo de tempo livre necessário.

Por fim, outra meta pretendida é o fortalecimento do grupo, para que, juntos, possam buscar soluções que visem melhorar o bemestar do trabalhador proveniente da banca de pesponto e costura manual. Isso inclui, por exemplo, reivindicações que envolvam desde a relação entre os próprios trabalhadores até sindicatos, intermediários e donos das fábricas de calçados.

\section{Referências Bibliográficas}

ANDRÉ, M. E. D. A. Etnografia da prática escolar. 11.ed. Campinas: Papirus, 2004.

AQUINO, C. A. B.; MARTINS, J. C. O. Ócio, lazer e tempo livre na sociedade do consumo e do trabalho. Revista mal-estar e subjetividade, Fortaleza, v.7, n.2, p.479-500, setembro 2007.

BARBOSA, A. de S.; MENDES, A. M. Capital, trabalho e formação da classe na indústria de calçados. Políticas públicas e sociedade. Revista do mestrado acadêmico em políticas públicas e sociedade da universidade estadual do Ceará. Fortaleza, v.1, n.5, p.63-71, janeiro 2003.

BARDIN, L. Análise de conteúdo. Lisboa: Edições 70, 1977.

CAMARGO, L. O. L. O que é lazer? 3.ed. São Paulo: Brasiliense, 1992.

CHENAVIER, R. Civilização de trabalho ou civilização do lazer? Estudos Avançados. São Paulo, v. 12, n. 32, 1998.

DE MASI, D. O ócio criativo. Rio de J aneiro: Sextante, 2000. MARCELLINO, N. C. Lazer e humanização. 8.ed. Campinas: Papirus, 2004.

MINAYO, M. C. de S. O desafio do conhecimento: pesquisa qualitativa em saúde. 4.ed. Rio de Janeiro: Hucitec-Abrasco, 1996.

NAVARRO, V. L. O trabalho e a saúde do trabalhador na indústria de calçados de Franca, SP. São Paulo em perspectiva, São Paulo, v. 17, n. 2, p. 32-41, junho 2003.

OLIVEIRA, C. B. Sobre tempo, trabalho e lazer na sociedade de consumo. Conexões, Campinas, v. 2, n. 1, 2004.

PORTUGUEZ, A. P. Consumo e Produção do Espaço Urbano. In:

Consumo e espaço: turismo, lazer e outros temas. São Paùlo: Roca, 2001. p.03-29.

PORTUGUEZ, A. P.; RABELO, D. L. Prazer e Contradição: Aspectos da Construção Segregadora dos Territórios de Lazer. In: PORTUGUEZ, A. P. Consumo e espaço: turismo, lazer e outros temas. São Paulo: Roca, 2001. p. 31-40.

SARRIERA, J. C.; PARADISO, A. C.; MOUSQUER, P. N.; MARQUES, L. F.; HERMEL, J. S. ; COELHO, R. P. S. Significado do tempo livre para 
adolescentes de classe popular. Psicologia ciência e profissão, Brasília, v. 27, n.4, p. 718-729, dezembro 2007.

WAICHMAN, Pablo. Tempo livre e recreação. Campinas: Papirus, 1997.

\section{Endereço para correspondência}

Suzi Mara Freitas

Av. Major Nicácio, 2433, CEP 14401-135, Franca-SP, Brasil

Endereço eletrônico: suzi.mf@hotmail.com

Daniela de Figueiredo Ribeiro

Av. Major Nicácio, 2433,CEP 14401-135, Franca-SP, Brasil

Endereço eletrônico: ribares@netsite.com.br

Antônio dos Santos Andrade

Avenida Bandeirantes, 3900, Campus Universitário FFCLRP/USP, CEP 14040-901

Ribeirão Preto-SP, Brasil

Endereço eletrônico: antandras@ffclrp.usp.br

Recebido em: 02/08/2009

Aceito para publicação em: 09/02/2010

Acompanhamento do processo editorial: Adriana Benevides Soares

\section{Notas}

* Obteve subsídios da Fundação de Amparo à Pesquisa do Estado de São Paulo (FAPESP) para realização da pesquisa.

** Doutora em Ciências pela FFCLRP-USP

$* * *$ Doutor

${ }^{1} \mathrm{O}$ nome do bairro é fictício.

${ }^{2} \mathrm{O}$ grupo de pesquisa era composto por nove estudantes que cursavam o terceiro ano de Psicologia e uma professora orientadora da mesma área. Esse grupo visava estudar o cotidiano de pessoas que trabalham no setor informal da indústria calçadista.

${ }^{3} \mathrm{O}$ projeto de pesquisa do presente estudo passou pela aprovação do Comitê de Ética em Pesquisa. Os participantes, antes que aceitassem fazer parte do estudo, foram esclarecidos sobre os objetivos e procedimentos do mesmo.

${ }^{4}$ Os nomes atribuídos aos entrevistados são fictícios. 